\title{
EARLY DETECTION OF ROOM FIRES THROUGH ACOUSTIC EMISSION
}

William Grosshandler and Emil Braun

Building and Fire Research Laboratory

Gaithersburg, Maryland 20899

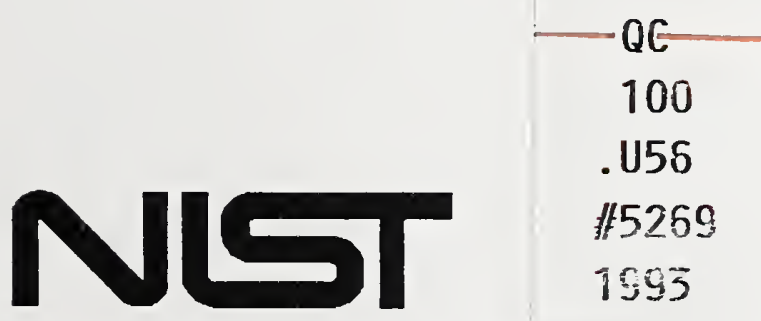

United States Department of Commerce

Technology Administration

National Institute of Standards and Technology 


\section{EARLY DETECTION OF ROOM FIRES THROUGH ACOUSTIC EMISSION}

William Grosshandler and Emil Braun

October 1993

Building and Fire Research Laboratory

National Institute of Standards and Technology

Gaithersburg, MD 20899

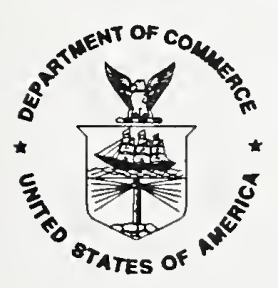

\section{U.S. Department of Commerce}

Ronald H. Brown, Secretary

Technology Administration

Mary L. Good, Under Secretary for Technology

National Institute of Standards and Technology

Arati Prabhakar, Director 

TABLE OF CONTENTS

ABSTRACT

INTRODUCTION

EXPERIMENTAL FACILITY

EXPERIMENTAL RESULTS

Electrical Heater Experiments

Gas Burner Experiments

DISCUSSION

CONCLUSIONS

ACKNOWLEDGEMENT

REFERENCES 


\title{
Early Detection of Room Fires Through Acoustic Emission
}

\author{
William Grosshandler \\ Emil Braun \\ Building and Fire Research Laboratory \\ National Institute of Standards and Technology \\ Gaithersburg, MD 20899
}

\begin{abstract}
Acoustic emission (AE) previously has been shown to be a viable concept for the early indication of an open flame impinging on various structural materials. To assess its effectiveness in a more realistic environment, experiments have been performed in a $2.5 \mathrm{~m}$ cubical room constructed of gypsum board and wood beams. AE transducers were mounted on top of the ceiling joists and behind the center wall panel on a vertical beam. Thermocouples were mounted at several points on the wall and ceiling, and an ionization-type smoke detector was attached to the ceiling near the door opening. Two distinct fire threats were examined: (a) a flaming fire consisting of a $0.3 \mathrm{~m}$ diameter pan fed with natural gas to produce a thermal load of between 12 and $125 \mathrm{~kW}$; and (b) a charring condition achieved by attaching a $550 \mathrm{~W}$ electrical heater to a vertical wooden beam located behind the gypsum board. A signal discernable above the background was recorded from at least one AE sensor in six of nine situations. In each case, measurable acoustic emission occurred before a noticeable increase in voltage from the thermocouple mounted adjacent to the $\mathrm{AE}$ sensor. The conclusion is that $\mathrm{AE}$ emission appears to be sufficiently sensitive to detect two distinct fire situations, and that an overheated condition in a wall or ceiling can be detected if it is not more than $3 \mathrm{~m}$ from the transducer. Additional experiments are required to determine the type of interfering $\mathrm{AE}$ signals that are likely to complicate the differentiation between a false and a true fire event.
\end{abstract}

\section{INTRODUCTION}

The heat produced by a small fire or by an electrical circuit overload will cause the materials surrounding the heat source to expand. If the affected components heat unevenly or are of dissimilar material so that expansion is not uniform, the stressed material may emit sound at frequencies up to 500 $\mathrm{kHz}$ when the stress is suddenly relieved. The boiling of trapped moisture or bursting of gas bubbles within a plastic also produces sound. There is a characteristic acoustic signature associated with these processes which can be used to detect a serious overheating event, possibly prior to ignition.

In a recent study ${ }^{1}$ the viability of using the acoustic signal emitted by a variety of structural materials exposed to nonuniform heating as an early indicator of a fire was assessed. The acoustic emission (AE) process, its application to fire detection, and the results of a series of tests were presented and the implications for fire protection were discussed. Piezoelectric transducers were mounted directly on beams of different structural materials, and the ultrasonic events resulting from a small flame placed under the beam were recorded. The number of $\mathrm{AE}$ events in a minute and the cumulative energy released during the heating cycle were found to provide a good measure of the overheated state of some of these materials before a significant temperature increase was indicated. The measured signals varied in energy and number with the type of material, the thickness of the specimen and heat flux. Wood was particularly susceptible to acoustic emission, producing more than 1000 events per minute in a solid fir board and $30 / \mathrm{min}$ in $13 \mathrm{~mm}$ thick plywood when the flame exceeded $1.0 \mathrm{~kW}$. A gypsum board produced 16 events in a minute. Differences in the cumulative energy released were also apparent, with plywood 
being four times more energetic than gypsum board even though the heating period for the wood was half as long.

The general behavior of the materials studied could be explained qualitatively by comparison to the simplified theory developed by Clough $^{2}$ which predicts acoustic emission during laser heating of a surface. In particular the following trends were found to be consistent with most of the limited amount of data collected:

- the energy detected increases about quadratically with increasing heat flux

- the energy detected increases directly with the square of the thermal expansion and specific volume, and indirectly with the thermal conductivity and specific heat

- the energy detected decreases with increasing sample thickness

A further description of the acoustic emission process can be found in reference 1 and in the review article by $\mathrm{Wadley}^{3}$. The number of emissions/minute varies for a given material in a manner similar to the energy. However, the absolute number of emissions could not be predicted a priori because the number of defects and the moisture content are highly variable for heterogeneous materials such as wood and gypsum board.

The previous work ${ }^{1}$ was performed on simply supported beams under quiescent conditions. In order to assess the potential for AE to detect the early stages of a fire, several large scale room tests were conducted in the present study. Two types of fire threats were investigated: (1) an electrical failure within the wall cavity, and (2) a small flaming fire in the compartment. These tests were designed to determine the energy and rate of events comparable to the laboratory experiments, but under closer-to-real construction conditions. For these experiments background noise was kept to a minimum. The impact of noise generated in a typical installation on the ability of AE detectors to discriminate between a fire and non-fire condition was not investigated in this report.

\section{EXPERIMENTAL FACILITY}

A full-scale room was constructed at BFRL's large fire test facility to simulate a portion of a typical residential structure. The room was nominally cubical, $2.4 \mathrm{~m}$ on a side, with a standard size door opening centered on one wall, as shown in the end view in Figure 1. The walls and ceiling were covered with commercially available $12 \mathrm{~mm}$ gypsum boards nailed to a wooden superstructure. The wall beams had a $37 \mathrm{~mm}$ by $88 \mathrm{~mm}$ cross-section and were placed on $0.6 \mathrm{~m}$ centers. The wooden ceiling beams were $37 \mathrm{~mm}$ by $176 \mathrm{~mm}$, butted to the wall supports (see Figure 2) and attached with long screws. The center portion of the ceiling was dropped by an amount equal to the height of the beams for ease of construction and instrumentation.

Three Physical Acoustic Corporation* piezoelectric transducers were mounted on the central wall and ceiling beams, located as shown in Figures 1 and 2 . The devices were coupled to the wooden surfaces with just enough silicone vacuum grease to hold them in place during the experiments. The vertical beam was notched to accommodate the transducer in a horizontal position. Signals from the transducers passed through PAC model 1220 A preamplifiers and a PAC model 3000 power supply, amplifier and signal processor. The response of the AE signal processor was previously found to depend strongly on the threshold and amplifier settings ${ }^{1}$. Total amplification factors of +86 to $+89 \mathrm{~dB}$ and a threshold level of $0.2 \mathrm{~V}$ were chosen. The dead time and time base were set at $1.0 \mathrm{~ms}$, and the update

\footnotetext{
*Certain commercial products are identified in this report in order to adequately specify equipment used. Such identification does not imply recommendation by the National Institute of Standards and Technology, nor does it imply that this equipment is the best available for the purpose.
} 


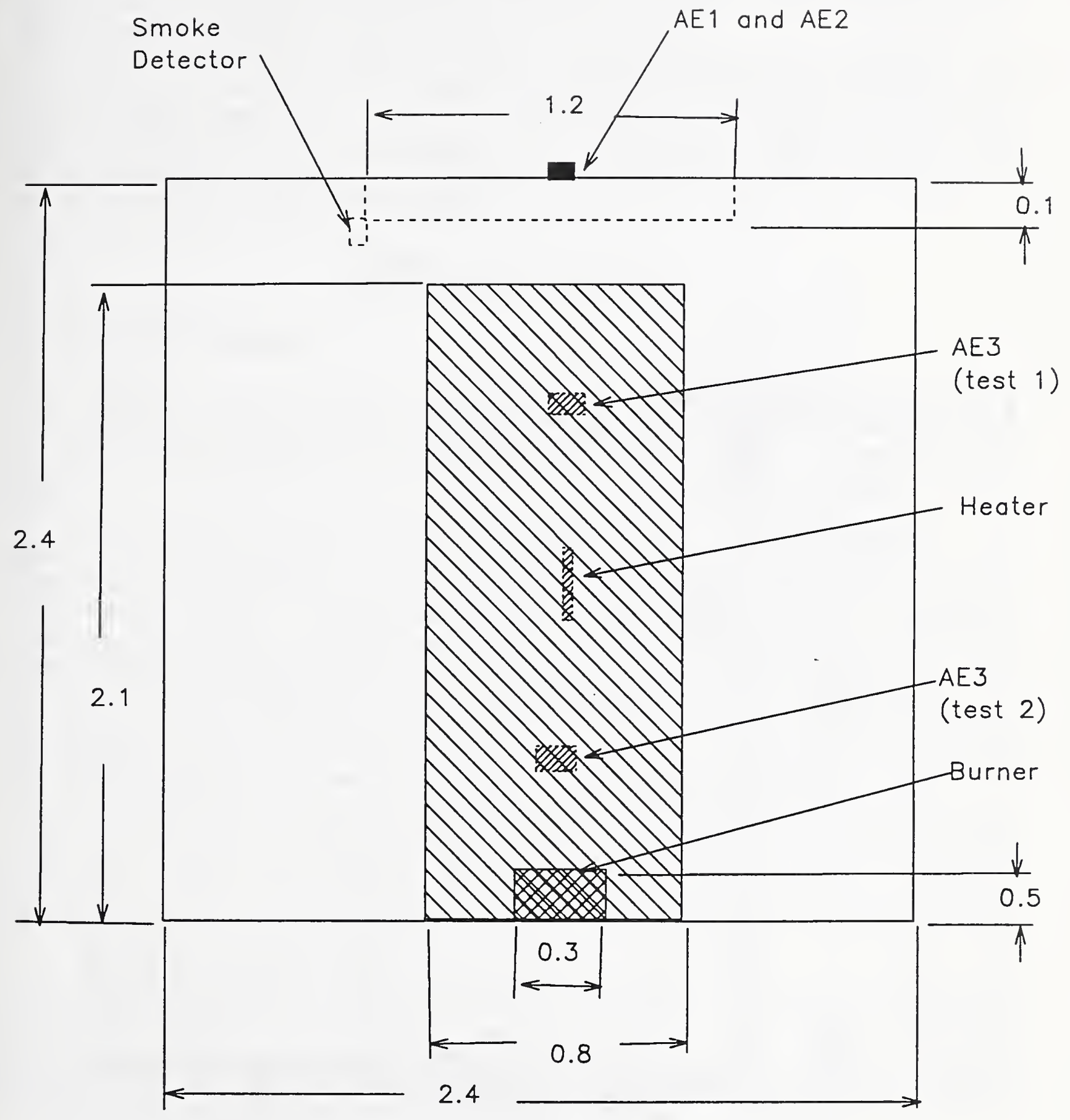

Figure 1. End view of full-scale facility for assessing performance of acoustic emission fire detector. Back wall can be seen as shaded through door way. 


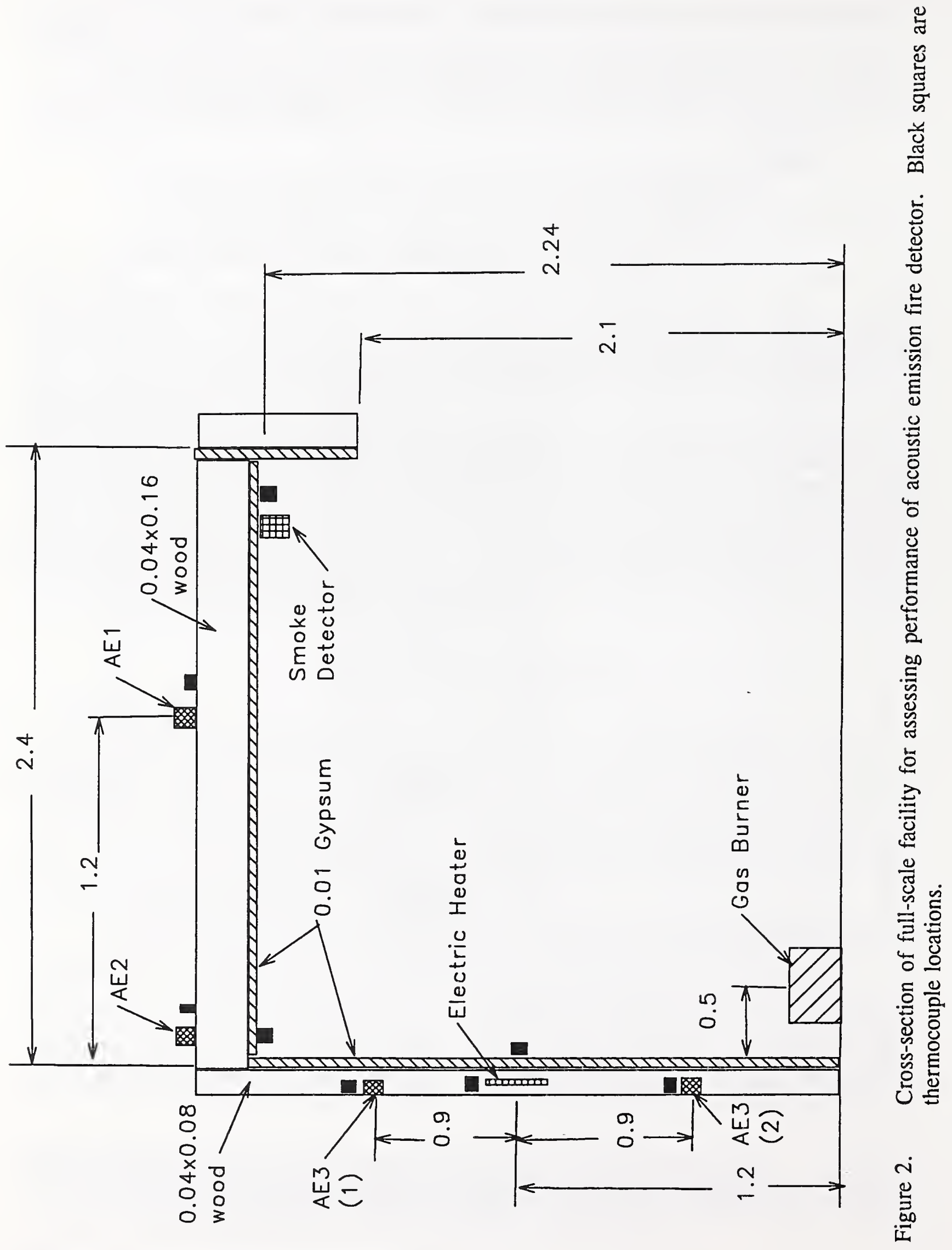


rate was fixed at $20 / \mathrm{s}$ for all the experiments.

Two different heat sources were used to simulate an overheated condition. The first was a 550 W electrical heater normally used for starting charcoal fires. As shown in the two figures, it was mounted on the center wall beam, halfway between the floor and ceiling. Copper conduit clamps were used to ensure good contact with the wood. The second heat source was a $0.3 \mathrm{~m}$ diameter natural gas pool fire, located on the centerline of the room close to the back wall.

Chromel-alumel thermocouples were used to monitor the temperature at the locations indicated by the black squares in Figure 2. The voltages were compensated and stored at ten second intervals in a data acquisition computer. Of particular interest were the temperatures at the location of the $\mathrm{AE}$ sensors, the temperature at the electrical heater, and the ceiling temperature above the gas fire. The temperature of an AC powered ionization smoke detector was also monitored. The smoke detector was installed on the ceiling close to the door opening.

\section{EXPERIMENTAL RESULTS}

\section{Electrical Heater Experiments}

Situations in which the products of pyrolysis and combustion are obstructed from entry into a room are difficult for many fire sensors to detect because traditional fire detection systems depend upon the convective transport of heat or mass from the fire to a remote sensor location. Two experiments were run to evaluate the $\mathrm{AE}$ sensors using an electrical heater to simulate an overheated condition in the wall cavity.

In the first test, AE sensor \#3 was located a little less than a meter above the heater. The background temperature and AE levels were monitored for 5.7 minutes, at which time full power was applied to the $550 \mathrm{~W}$ electrical heater. Figure 3 is a record of the temperatures measured during the seven minutes of heating. The temperature of the wood close to the electrical heater, $\mathrm{T}_{\mathrm{b}}$, increased rapidly once the electricity was applied, reaching a maximum of $180{ }^{\circ} \mathrm{C}$ above the ambient at the end of the heating period. The temperature, $T_{w}$, inside the room on the other side of the wall from the heater rose $22{ }^{\circ} \mathrm{C}$ above the environment, while the temperature at the location of the smoke detector, $\mathrm{T}_{\mathrm{d}}$, did not increase by a discernible amount. Because AE3 was located above the heating element, natural convection caused a significant temperature increase in its environment. The test was terminated when the operational temperature exceeded $50{ }^{\circ} \mathrm{C}$ in order to avoid damage to the transducer.

One emission event was recorded by AE3 during the 5.7 minute background check; none was recorded by $\mathrm{AE} 1$ or $\mathrm{AE2}$. $\mathrm{AE} 2$ did not respond at all during the heating period either, while $\mathrm{AE} 1$ produced two emissions. A large amount of activity was recorded by AE3, as shown in Figure 4. After a 1.3 minute delay, the number of emissions, $N$, suddenly jumped, with emissions continuing at a steady pace until 9.6 minutes, when the transducer was removed to prevent it from overheating. The cumulative energy, $\mathrm{E}$, increased in a parallel manner.

The curve in Figure 4 marked "rate" is the rate of emission calculated by averaging three consecutive emissions over the time between them. Because three emissions can occur within milliseconds of each other, the rate is artificially capped by limiting the smallest interval to one second. Once the rate exceeds the background level (less than $0.18 / \mathrm{min}$ in this case) by more than an order of magnitude, its absolute value is not critical to the analysis. The total number of emissions was measured to be 305 , yielding an average rate over the heating period of $78 / \mathrm{min}$.

The smoke detector did not respond at all in this first test, nor did the two AE transducers mounted in the ceiling indicate an overheated situation. While AE3 did produce a strong signal within a minute and one half of the power being applied, the thermocouple provided an equally early indication of the heating. The wall panels and vertical beam were replaced and a second test was run in which transducer AE3 was located below the heating element, where the temperature increase would be limited 


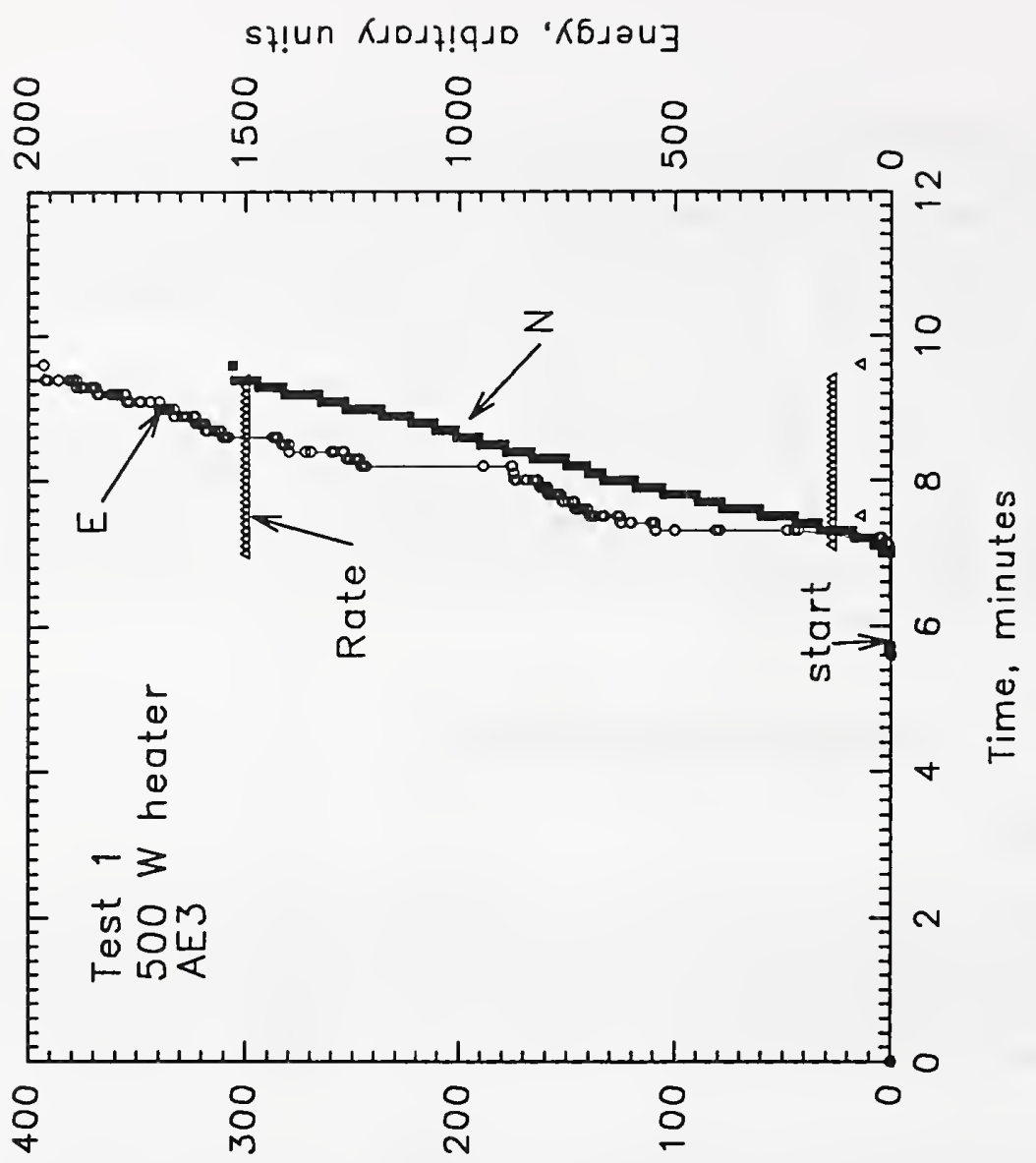

$(u ! m / l)$ ofod so 'suo!ss!m

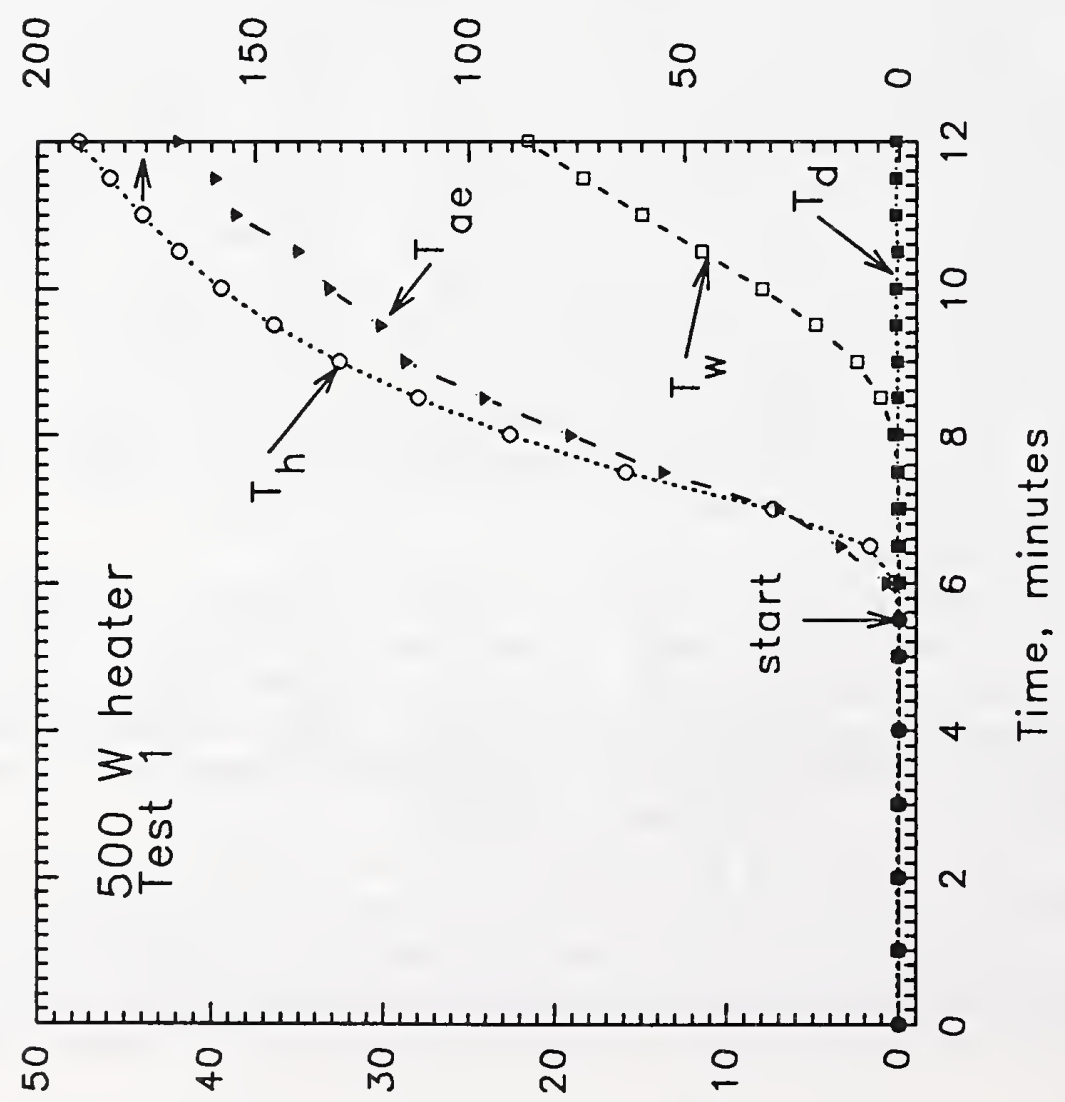

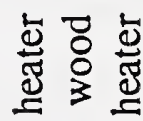

กี่ 象象 造造变

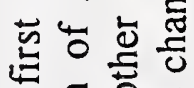

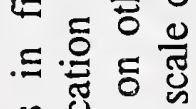

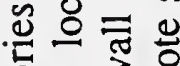

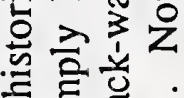
$\underline{\Xi} \dot{0}$ 参宫客 등 웡 的灵 - 동 的芯异总 ․ㅡㄹ 品焉 证希言

(ग) asdajou! adnfodadual 


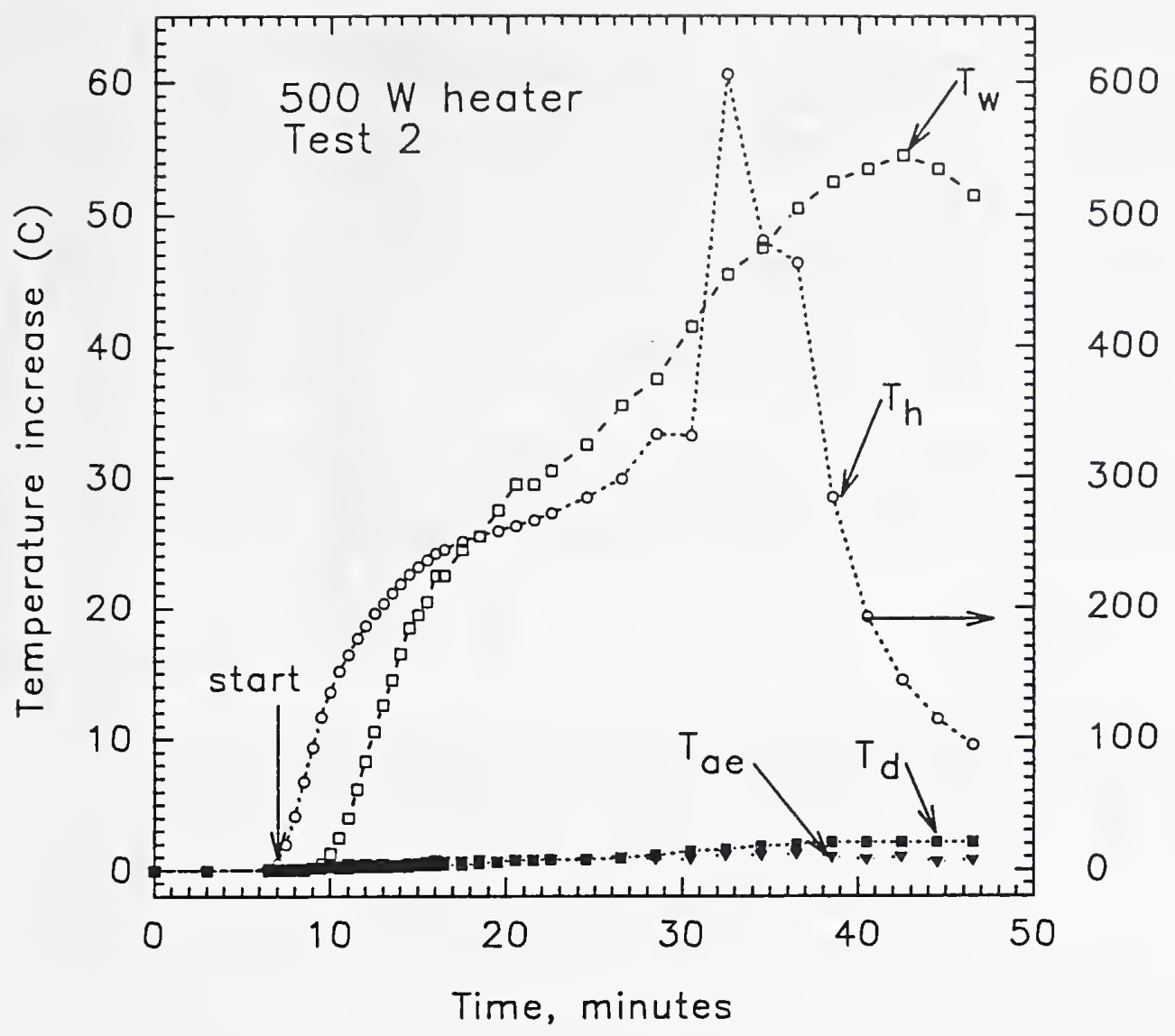

Figure 5. Temperature histories in second electrical heater experiment. Subscripts imply location of AE3 (ae), wood surface near heater (h), back-wall on other side from heater (w) and smoke detector (d).

to conduction through the wood. This arrangement allowed the experiment to be run for a longer period of time before a secondary effect of temperature on the transducer itself could become significant.

Temperature profiles taken during the second test are shown in Figure 5. After a background check period of 6.5 minutes, power to the heater was started and the temperatures increased in a manner similar to test \#1. The temperature measured adjacent to the heater, $T_{b}$, rose in an orderly manner and appeared to level off at 30 minutes, when a $300^{\circ} \mathrm{C}$ jump was observed, followed by a steep decline to the 46 minute point, when the power was turned off. Inspection of the heater, vertical beam, and gypsum board after the system had cooled indicated that a char layer had formed about $10 \mathrm{~mm}$ deep under the heater. A number of crevices had formed in the wood and the surface was disrupted, leading to the conjecture that the thermocouple had become dislodged from the surface, recontacted the surface as it expanded, and then lost contact as buckling of the surface occurred. The temperature in the room directly on the other side of the wall from the heating element, $T_{w}$, increased by $55^{\circ} \mathrm{C}$. The temperature at transducer AE3, $T_{a c}$, increased less than two degrees during the entire test, and the temperature increase near the smoke detector, $T_{d}$, was about four degrees.

The amplification of $\mathrm{AE}$ transducers 1 and 2 was increased $3 \mathrm{~dB}$ to $89 \mathrm{~dB}$ in this second test. The increased amplification caused the background emission to rise to a level of $4 / \mathrm{min}$ from AE2. Amid this high background only one emission had enough energy to be recognizable as occurring during the heating period. There was no background emission measured by AEl, located on top of the center beam 


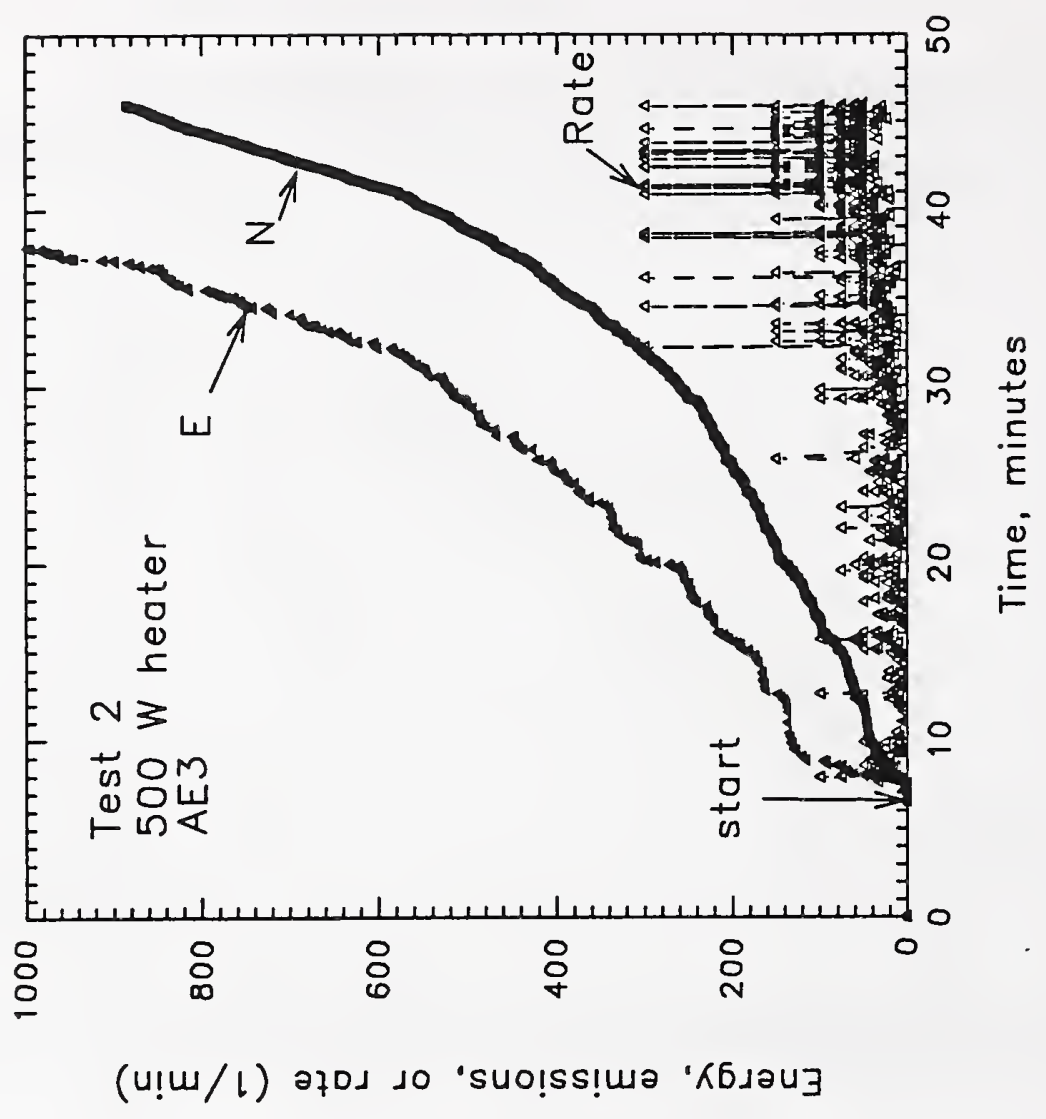

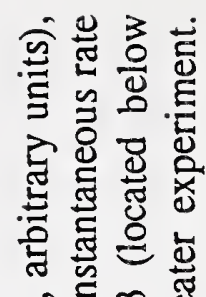
包哲 ไูป สี ฮิ 는 ลิ

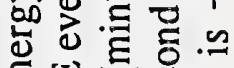
क्ष

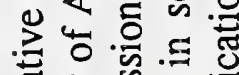
总总㤩言

$\therefore$

㟧

主

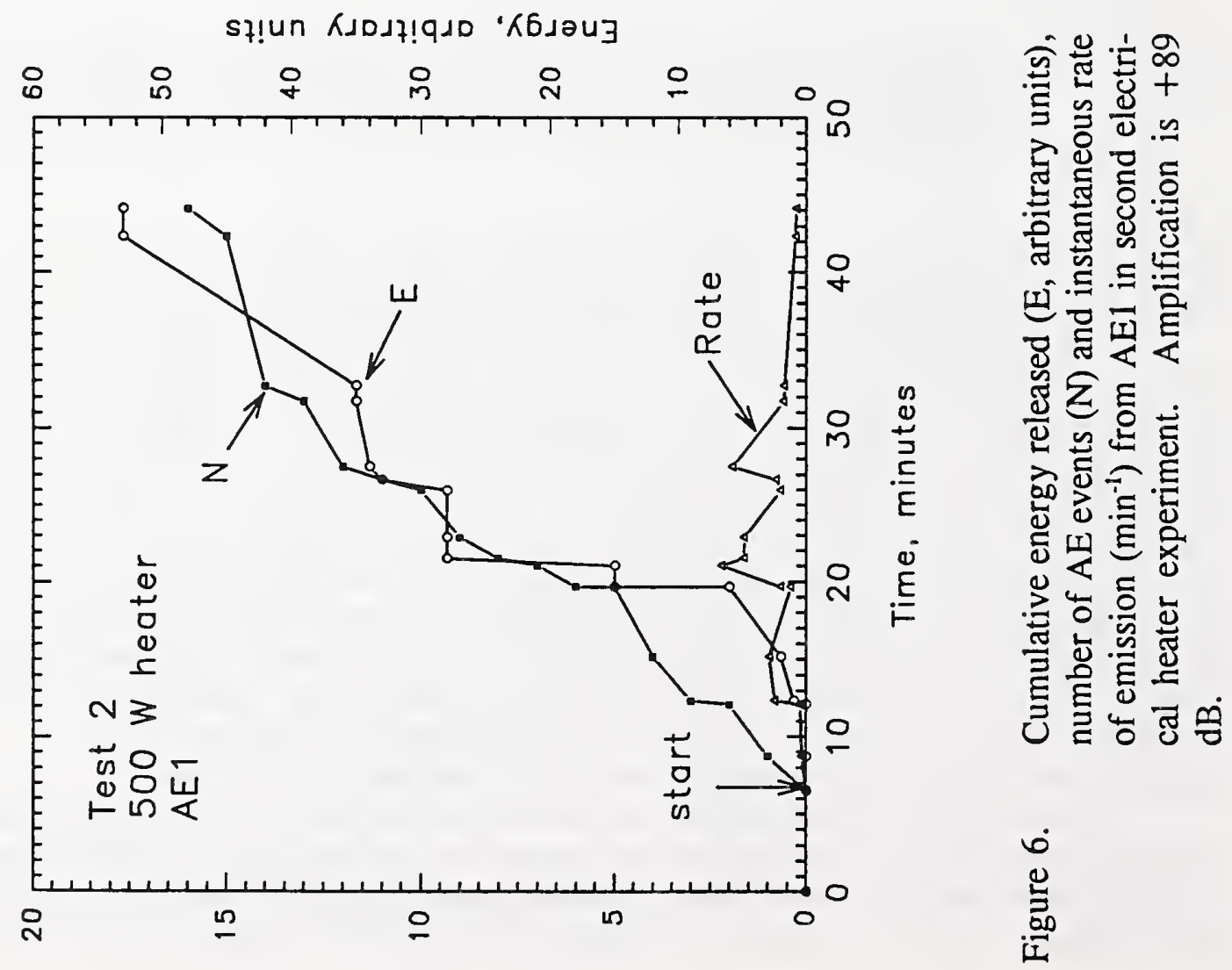

(u!m/l) ә70د رo 'suo!ss!m 
in the ceiling, in spite of the increase in amplification. During the forty minute heating period there were 16 emissions, yielding an average rate of $0.43 / \mathrm{min}$, with the first emission occurring about two minutes after the heater was started. Figure 6 is a plot of the number of emissions and cumulative energy from AE1. The instantaneous rate of emission approached $1 / \mathrm{min}$ about five minutes into the heating period, which is well above the background signal measured with this particular transducer. The amplification was maintained at $86 \mathrm{~dB}$ for $\mathrm{AE3}$. Within a minute and a half, the transducer began detecting emissions at a rate in excess of $50 / \mathrm{min}$, following the initial period without heat during which no emissions were measured. Figure 7 shows the history of cumulative energy and emission number, with an accelerating number of events occurring about 30 minutes into the test. The instantaneous rate of emission exceeded $300 /$ min (the maximum imposed by the data analysis method) many times during the latter period of heating.

Wisps of smoke were first observed above the room about six minutes into test two. Very little smoke was noticed within the room, but an odor was unmistakably present. The smoke detector located in the test room did not respond at any time during the experiment.

\section{Gas Burner Experiments}

The gypsum boards and vertical wood beam were replaced, and AE3 was relocated as in test number 1 , about $0.9 \mathrm{~m}$ above the mid-height of the room. After an initial five minutes of background data, the gas flow to the burner was set to deliver $12 \mathrm{~kW}$ of heat to the room for a ten minute period. At that time, the fire was increased to $25 \mathrm{~kW}$, followed by a $25 \mathrm{~kW}$ increase each five minute interval later, reaching a maximum heat input of $125 \mathrm{~kW}$ at 35 minutes into the test.

Figure 8 is a plot of the temperature increase in the room. The maximum temperature was located on the ceiling above the burner. The largest increase was $210{ }^{\circ} \mathrm{C}$, measured just before the burner was extinguished. The temperature increase measured at the smoke detector was similar in magnitude, and both temperatures responded within seconds to the changes in gas flow. The increasing size of the fire is indicated by the vertical arrows in the figure. The temperature increase above the ceiling joist, where AE1 and AE2 were located, was indiscernible until the fire reached its maximum value near the end of the experiment. The transducer mounted in the wall, AE3, increased two degrees in the first five minutes of the fire, and $10^{\circ} \mathrm{C}$ after 15 minutes of burning. The temperature at AE3 exceeded $50{ }^{\circ} \mathrm{C}$ about 30 minutes into the experiment.

The amplification on AE2 was reduced to $86 \mathrm{~dB}$ to eliminate the large background signal observed in the previous test. AE1 and AE3 were set to an amplification factor of $+89 \mathrm{~dB}$. During the five minute background check, one emission was recorded by AE1 and two each by AE2 and AE3. For the transducer located above the ceiling joist in the center of the room, $A E 1$, the emission rate exceeded the background twenty minutes after ignition. The number of events and cumulative energy recorded by AE1 are shown in Figure 9.

AE3 began to detect the fire seven minutes after the burner was lit. From Figure 10, the steady increase in the number of AE events can be observed even when the fire is $25 \mathrm{~kW}$ and smaller. The greatest activity was recorded on channel 2 from the transducer located above the corner of the room closest to the centerline of the burner. This is shown in Figure 11. A maximum emission rate of $16 / \mathrm{min}$ was found ten minutes into the burn. The average rate of emission over the 31 minutes that the burner was lit was $1.2 / \mathrm{min}$.

The smoke level was very light with the natural gas burner. The flames reached the ceiling about $50 \%$ of the time when the gas flow was set to $100 \mathrm{~kW}$. After the test was completed, inspection revealed that the ceiling was lightly scorched in a $0.3 \mathrm{~m}$ circle directly above the burner, but that the paper layer on the gypsum board had not been ignited. The ionization smoke detector did not detect the presence of smoke anytime during the 38 minute test. 


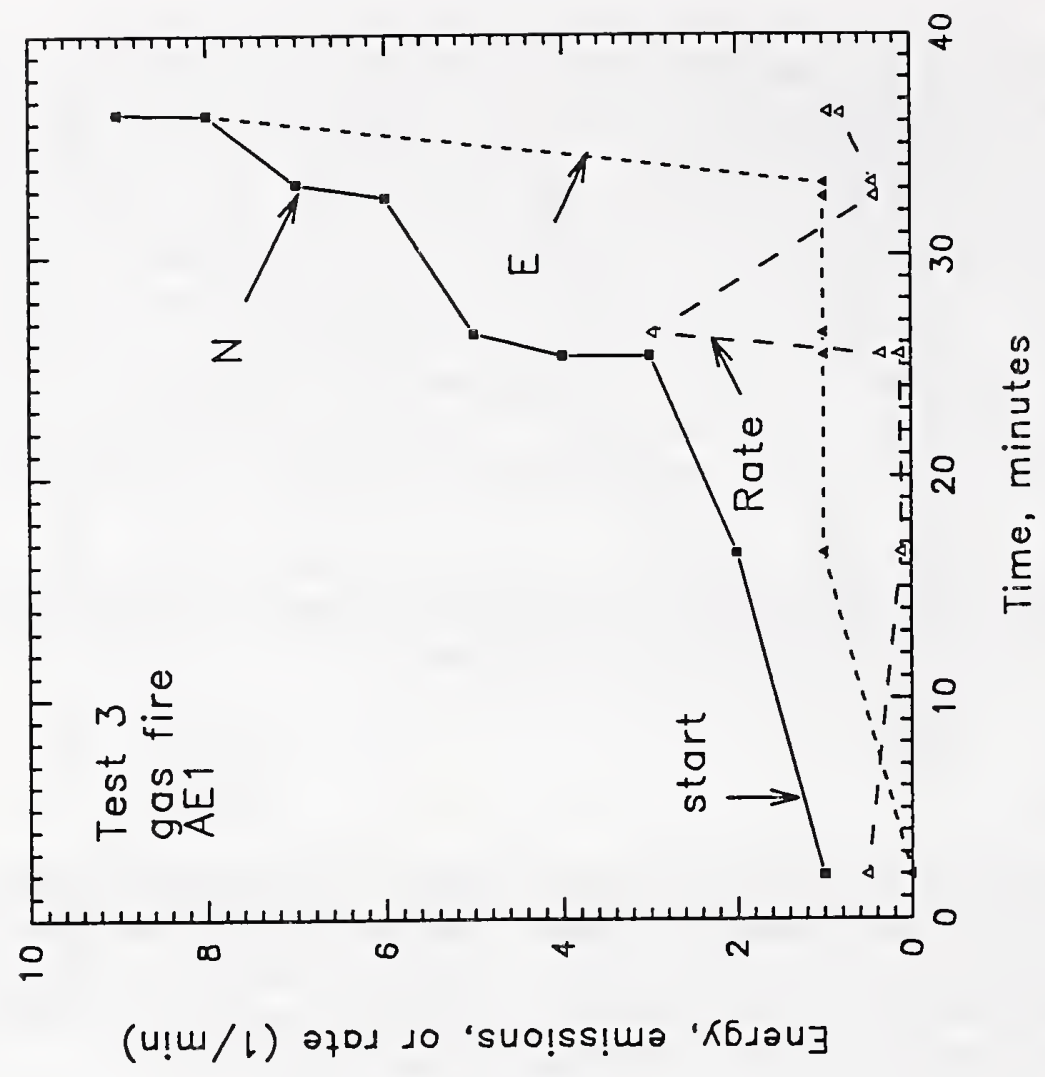

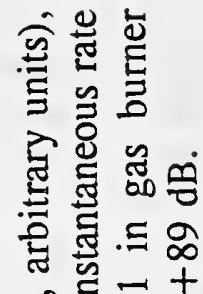
핌표 马ु 导递思

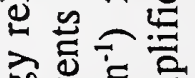

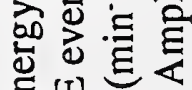
可 단

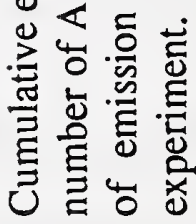

$a^{\circ}$

峁

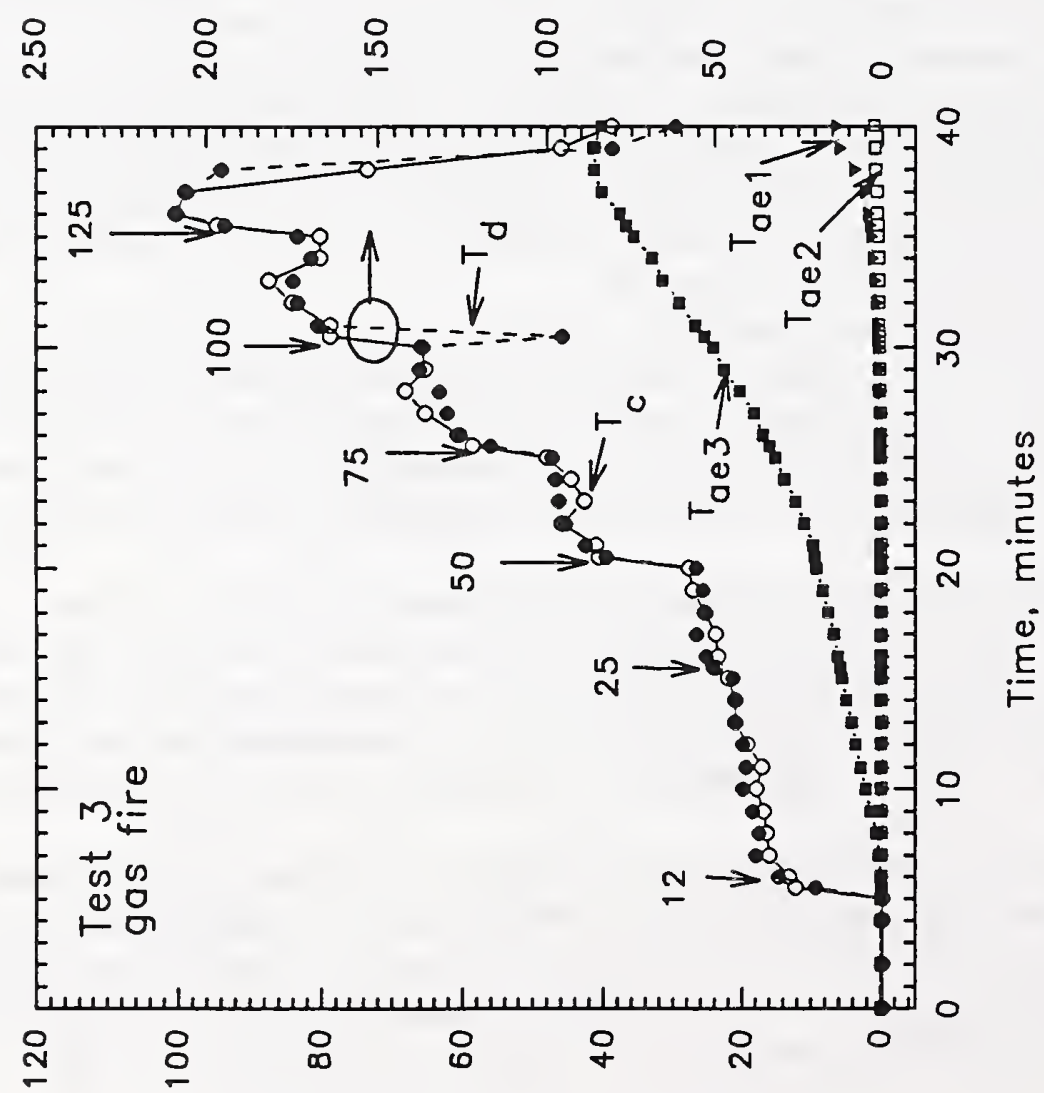

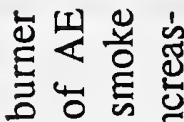
들

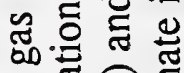
䟢 군은 문 至空导导

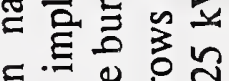
.

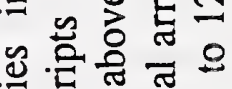
.

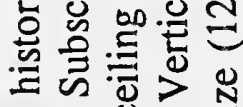

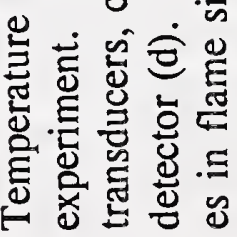

(ว) ascanou! asnfodadual 


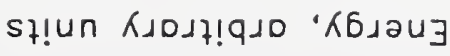
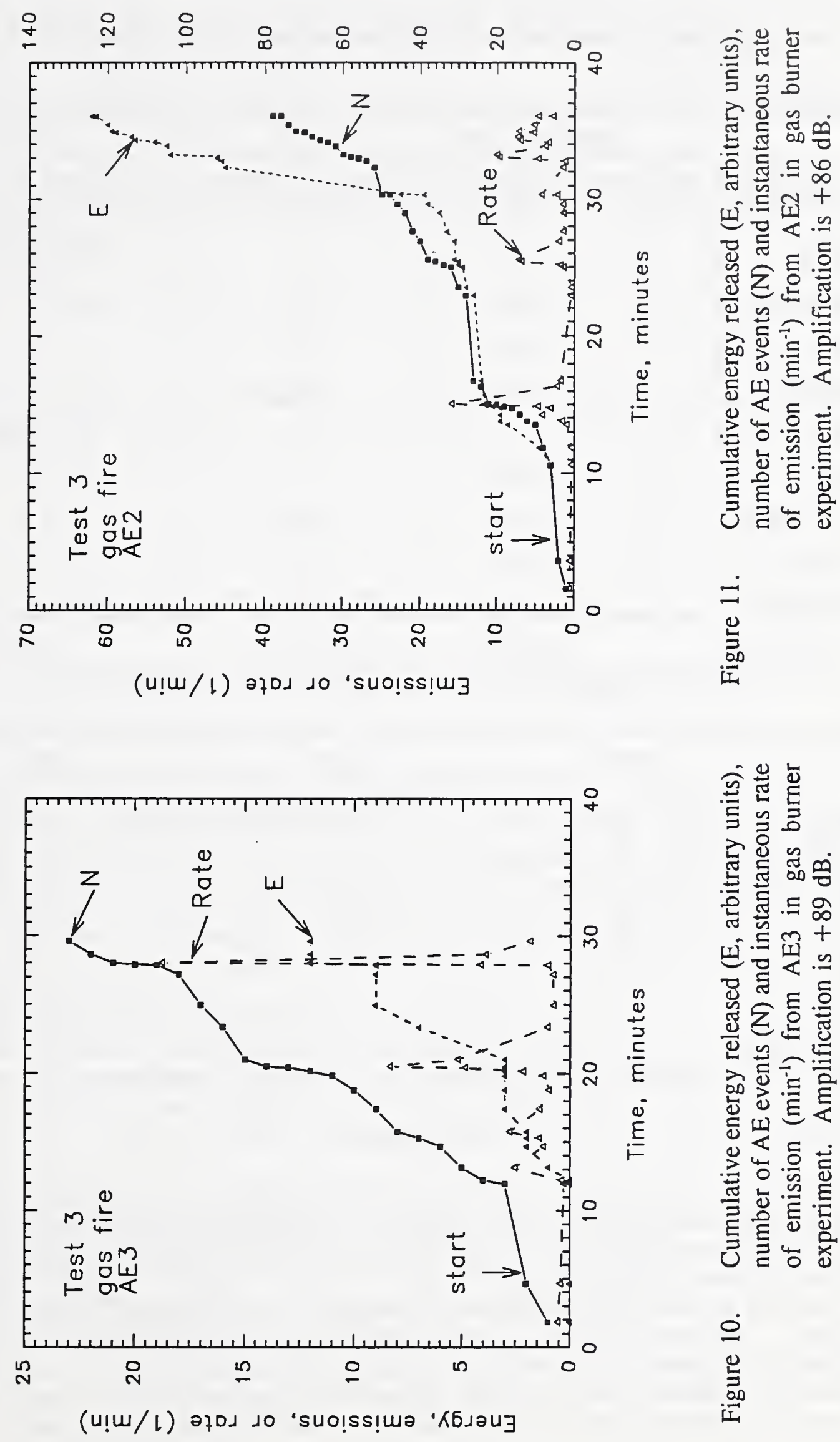

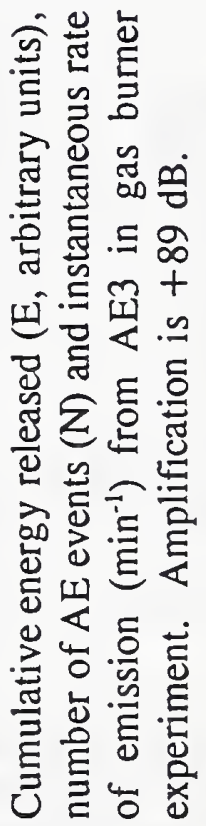

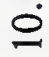

龸 
Table 1.

Summary of background and average response of AE transducers to $550 \mathrm{~W}$ electrical heater.

\begin{tabular}{|l|c|c|c|c|c|c|}
\hline \multirow{2}{*}{} & \multicolumn{2}{|c|}{$\mathrm{AE} \# 1$} & \multicolumn{2}{c|}{$\mathrm{AE} \# 2$} & \multicolumn{2}{c|}{ AE \#3 } \\
\cline { 2 - 7 } & Background & Response & Background & Response & Background & Response \\
\hline Test 1: & & & & & & \\
Rate, min' & & & & & \\
Duration, ms & 0 & 0.34 & 0 & 0 & 0.18 & 78.0 \\
Energy, a.u. & 0 & 228 & 0 & 0 & 54 & 89 \\
Amplitude, a.u. & 0 & 14.5 & 0 & 0 & 3.0 & 6.4 \\
\hline Test 2: & & 56 & 0 & 0 & 51 & 47 \\
Rate, min-1 & 0 & 0.43 & 4.15 & 4.37 & 0 & 22.4 \\
Duration, ms & 0 & 61 & 54 & 32 & 0 & 97 \\
Energy, a.u. & 0 & 3.3 & 1.4 & 1.0 & 0 & 4.9 \\
Amplitude, a.u. & 0 & 41 & 36 & 37 & 0 & 46 \\
\hline
\end{tabular}

Table 2. Summary of background and average response of AE transducers to natural gas pool fire.

\begin{tabular}{||l|c|c|c|c|c|c||}
\hline \multirow{2}{*}{} & \multicolumn{2}{|c|}{ AE \#1 } & \multicolumn{2}{c|}{ AE \#2 } & \multicolumn{2}{c|}{ AE \#3 } \\
\cline { 2 - 7 } & Background & Response & Background & Response & Background & Response \\
\hline Rate, min ${ }^{-1}$ & 0.20 & 0.25 & 0.40 & 1.19 & 0.40 & 0.85 \\
\hline $\begin{array}{l}\text { Duration, } \\
\text { ms }\end{array}$ & 15 & 20 & 67 & 68 & 0 & 20 \\
\hline $\begin{array}{l}\text { Energy, } \\
\text { a.u. }\end{array}$ & 0 & 1.1 & 2.0 & 3.2 & 0 & 0.6 \\
\hline $\begin{array}{l}\text { Amplitude, } \\
\text { a.u. }\end{array}$ & 40 & 36 & 42 & 43 & 41 & 57 \\
\hline \hline
\end{tabular}

\section{DISCUSSION}

The average energy, amplitude and duration of each acoustic emission were measured during the experiments. This information is useful in helping to discriminate a response to a fire from the background emission. Tables 1 and 2 are summaries of the average data for the electrical heater and gas burner experiments, respectively.

Referring to Table 1, the background signal can be seen to be zero in four of the six measurements. The acoustic emission rate from AE3 in test 1 is more that two orders of magnitude higher than the background. The duration and energy of an average response are about twice the background level. On the other hand, AE2 was unable to detect the hazard in either test. The amplification was too low to produce a response in test 1 . In test 2 the noise was amplified as much as 
Table 3. Characteristic response times comparing acoustic emission to a $6{ }^{\circ} \mathrm{C}$ temperature rise in two different fire situations.

\begin{tabular}{|c|c|c|c|}
\hline \multirow[b]{2}{*}{ Detector } & \multicolumn{3}{|c|}{ Time to Respond } \\
\hline & Test 1 (elec.) & Test 2 (elec.) & Test 3 (gas) \\
\hline \multicolumn{4}{|c|}{$\frac{\text { Acoustic Emission }}{\underline{\text { Detector }}}$} \\
\hline $\mathrm{AE} 1$ & $>5.8 \mathrm{~min}$ & $6 \mathrm{~min}$ & $21 \mathrm{~min}$ \\
\hline AE2 & $>5.8 \mathrm{~min}$ & $>39.5 \mathrm{~min}$ & $9 \mathrm{~min}$ \\
\hline AE3 & $1.3 \mathrm{~min}$ & $1.5 \mathrm{~min}$ & $7 \mathrm{~min}$ \\
\hline \multicolumn{4}{|c|}{ Thermocouple } \\
\hline $\mathrm{T}_{\mathrm{ae} 1}$ & $>5.8 \mathrm{~min}$ & $21.7 \mathrm{~min}$ & $33.8 \mathrm{~min}$ \\
\hline $\mathrm{T}_{\mathrm{ae} 2}$ & $>5.8 \mathrm{~min}$ & $33.8 \mathrm{~min}$ & $>34.8 \mathrm{~min}$ \\
\hline $\mathrm{T}_{\mathrm{ae3}}$ & $1.5 \mathrm{~min}$ & $>39.5 \mathrm{~min}$ & $10.8 \mathrm{~min}$ \\
\hline $\mathrm{T}_{\text {smoke det }}$ & $>5.8 \mathrm{~min}$ & $>39.5 \mathrm{~min}$ & $0.2 \mathrm{~min}$ \\
\hline $\mathrm{T}_{\max }$ & $0.8 \mathrm{~min}$ & $0.6 \mathrm{~min}$ & $0.1 \mathrm{~min}$ \\
\hline
\end{tabular}

any signal. The average duration, energy and amplitude measured by AE2 provided no indication of a fire threat.

The emission rates from AE2 and AE3 in response to the gas burner fire are two to three times greater than the background levels. (See Table 2.) The average duration, energy and amplitude are all larger than the background, as well, although in the case of AE2 the differences between the background and the response for the average duration and amplitude are not statistically meaningful. The emission rate from AE1 is only slightly higher than the background, and the amplitude is less. The non-zero average energy level for this transducer provides a bit of reinforcement that the AE events are in response to an overheated condition.

The response time of the AE detector can be characterized in a number of ways. For the purpose of discussion, let the response time be defined as the delay between the onset of heating and a measured signal (i.e., emission rate) equal to at least twice the background level. The response of the AE detector can be compared to the time it takes for the thermocouple adjacent to it to increase $6{ }^{\circ} \mathrm{C}$ above the ambient condition. Table 3 lists these two characteristic times determined from the three tests which were conducted.

AE3 detected all three hazards, responding between 1.3 and 7 minutes after the heating period began. The other AE transducers failed to respond at least once within the allotted test time. The thermocouple located at each AE device in all cases took longer to exceed the threshold temperature than the corresponding AE transducer. While the thermocouple located directly above the gas burner responded to the temperature increase within seconds of when the fire was lit, one does not know a priori the location of the maximum temperature in the room. 


\section{CONCLUSIONS}

performed:

The following conclusions can be drawn based upon analysis of the experiments which were

1. The acoustic emission activity measured previously ${ }^{1}$ in $0.5 \mathrm{~m}$ simply supported beams of wood and gypsum board exposed to a small open flame also occurs when these same materials are heated in a structure similar to a full-scale room environment.

2. An acoustic emission transducer is capable of detecting in a full-scale room an open natural gas fire greater than $12 \mathrm{~kW}$ and a $550 \mathrm{~W}$ electrical heater in contact with a wooden beam at a distance up to $3 \mathrm{~m}$ from the heat source.

3. Under the conditions similar to those in the current test, an acoustic emission transducer may detect the threat of a fire as quickly as or faster than a thermocouple or smoke detector. (No claim is made that the $\mathrm{AE}$ device would respond more quickly than a smoke detector under other realistic fire conditions.)

4. Additional research is required to identify non-fire sources of $A E$ emission so that a threatening situation can be unambiguously discriminated from a non-threatening situation.

\section{ACKNOWLEDGEMENT}

The authors wish to acknowledge Roger Clough of the Materials Science and Engineering Laboratory, who provided the acoustic emission measuring equipment and guidance for its application. Assistance from R. Zile, L. DeLauter and G. Roadarmel in conducting the experiments and from Isa Vazquez during the data reduction is also gratefully acknowledged.

\section{REFERENCES}

1. Grosshandler, W.L., and M. Jackson, "Acoustic Emission of Structural Materials Exposed to Open Flames," Fire Safety Journal, in press, 1993.

2. Clough, R.B., "The Energetics of Acoustic Emission Source Characterization," Materials Evaluation 45, (1987) 556-563.

3. Wadley, H.N.G., "Acoustic Emission: Nature's Ultrasound," in Review of Progress in Quantitative Nondestructive Evaluation, Vol. 5A, D.O. Thompson and D.E. Chimenti, Eds., Plenum Publishing Corp., 1986, pp. 271-293. 


\section{NIST-114}

(REV. 9-92)

AOMAN 4.09
U.S. DEPARTMENT OF COMMERCE NATIONAL INSTITUTE OF STANDARDS AND TECHNOLOGY

MANUSCRIPT REVIEW AND APPROVAL

INSTRUCTIONS: ATTACH ORIGINAL OF THIS FORM TO ONE (1) COPY OF MANUSCRIPT AND SEND TO:

THE SECRETARY, APPROPRIATE EDITORIAL REVIEW BOARD.

TITLE AND SUBTITLE (CITE IN FULL)

Early Detection of Room Fires Through Acoustic Emission

CONTRACT OR GRANT NUMBER

AUTHOR(S) (LAST NAME, FIRST INITIAL, SECOND INITIAL)

Grosshandler, W., Braun E.

LABORATORY ANO DIVISION NAMES (FIRST NIST AUTHOR ONLY)

Building and Fire Research Laboratory/Fire Science Division

SPONSORING ORGANIZATION NAME AND COMPLETE ADDRESS (STREET, CITY, STATE, ZIP)

\section{RECOMMENDED FOR NIST PUBUCATION}

\begin{tabular}{|}
\hline RE \\
\hline SU \\
\hline
\end{tabular} JOURNAL OF RESEARCH (NIST JRES) J. PHYS. \& CHEM. REF. DATA (JPCRD) HANDBOOK (NIST HB) SPECIAL PUBUCATION (NIST SP) TECHNICAL NOTE (NIST TN)

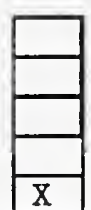
MONOGRAPH (NIST MN) MATL STO. REF. DATA SERIES (NIST NSRDS) FEDERAL INF. PROCESS. STOS. (NIST FIPS) UST OF FUBUCATIONS (NIST LP) NIST INTERAGENCY/INTERNAL REPORT (NISTIR)

\begin{tabular}{|l|l|l|l|l|l|}
\hline RECOMMENDED FOR NON-NIST PUBLICATION (CITE FULLV & & U.S. & & FOREIGN
\end{tabular}

L U.S. L $\square$ FOREIGN

SUPPLEMENTARY NOTES
(ET) use omin

\begin{tabular}{|l|l|}
\hline EAO CONTAOL MNAT & \\
\hline $\begin{array}{l}\text { PUBUCATION REPORT NUMEER } \\
\text { NISTIR 5269 }\end{array}$ & CATEOORY CODE \\
\hline $\begin{array}{l}\text { PUBUCATION DATE } \\
\text { OCtOBET 1993 }\end{array}$ & NUMBER PRINTEO PAGES \\
\hline
\end{tabular}

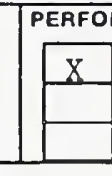

NIST/GAITHERSBURG

NIST/BOULER

JILA/BOULOER

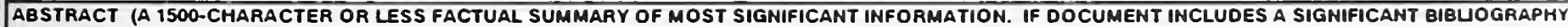
OR UTERATURE SURVEY, CITE IT HERE. SPEL OUT ACRONYMS ON FIRST REFERENCE.) (CONTINUE ON SEPARATE PAGE, IF NECESSARY.)

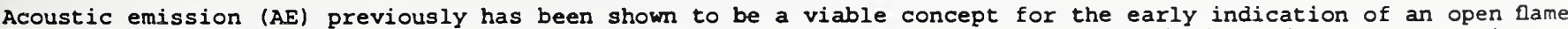

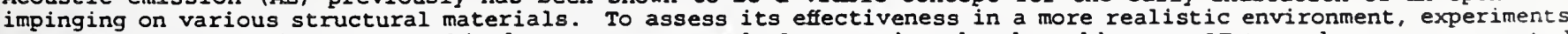

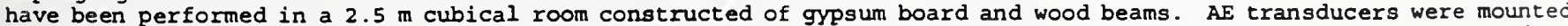

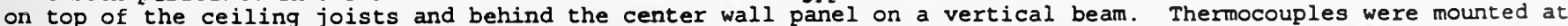

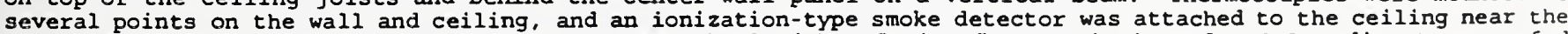

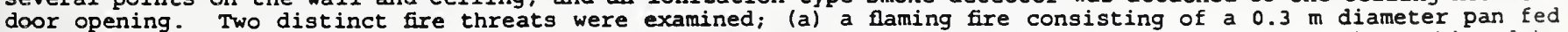

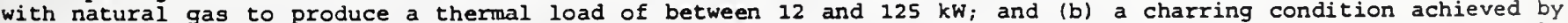

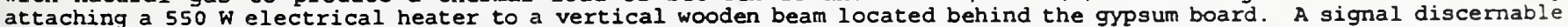

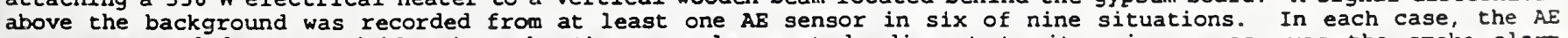

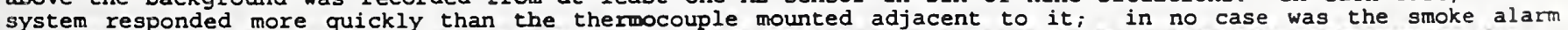

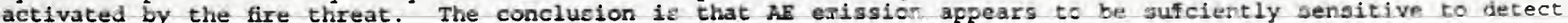

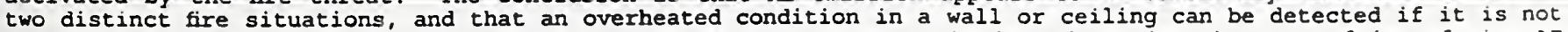

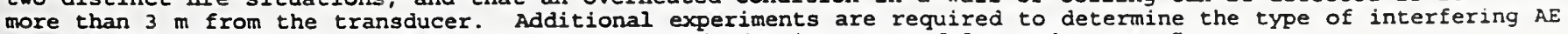
signals that are likely to complicate the differentiation between a false and a true fire event.

KEY WORDS (MAXIMUM 9 KEY WORDS; 28 CHARACTERS AND SPACES EACH; ALPHABETICAL ORDER; CAPITAUZE ONLY PROPER NAMES)

Acoustic properties: acoustic sensors: fire detection AVAILABIUTY

$\mathrm{X}$

UNUMITEO

$\mathrm{X}$
FOR OFFICLAL DISTRIBUTION. DO NOT RELEASE TO NTIS.

ORDER FROM SUPERINTENDENT OF DOCUMENTS, U.S. GPO, WASHINGTON, D.C. 20402 ORDER FROM NTIS, SPRINGFIELD, VA 22161
NOTE TO AUTHOR(S) IF YOU DO NOT WISH THIS MANUSCRIPT ANNOUNCED BEFORE PUBLCATION. PLEASE CHECK HERE 


